\title{
Métodos e Processos Administrativos do Marquês de Pombal
}

\section{Luiz Pinto}

\section{$\mathrm{S}$}

ERvira Sebastião José de Carvalho e Melo, conde de Oeiras e marquês de Pombal, como diplomata ilustre, na Inglaterra e na Áustria, coincidindo êsse seu estágio na Europa com a luta de idéias que gerou o enciclopedismo, luta "a que Portugal quase ficara alheio dentro da sua educação semifanática e retrógrada, sob as peias da Inquisição".

Assim, com aquela aprendizagem liberal, Carvalho e Melo retornou à velha pátria portuguêsa cheio de idéias novas, constituindo-se, sem demora, o varão singular do reinado de D. José I. Clero, nobreza, povo, todos ouviam a sua palavra, auscultavam-lhe o pensamento e não se contrapunham aos seus atos, às vêzes até do mais puro arbítrio, pois que, mesmo liberal, Pombal era ao mesmo tempo "despótico e tirânico".

Em Portugal, antes de sua atuação na política e na administração do Brasil, o marquês de Pombal praticara atos de coragem e decisão, que muito o projetaram, destacando-se entre êles a abolição da Inquisição, e do triste espetáculo dos seus autos-de-fé, como também a atitude que refletia as idéias dos pensadores gauleses, que fôra a extinção da odienta distinção entre cristãos novos e cristãos velhos. (2)

Com êsses atos fortes e decisivos, Sebastião José de Carvalho e Melo fazia desaparecer o espírito de rixa contra judeus e suspeitos de judaísmo, como ainda de sectarismo em matéria de religião, que tanto agoniaram a gente portuguêsa.

Chegado ao Brasil, não tardou Pombal de assenhorear-se das anormalidades e anomalias existentes na administração e na política colonial, produto de lutas, ambições e ânsia de conquista.

Se bem que, naqueles "meados do século XVIII, o Brasil já houvesse atingiido a sua máxima expansão territorial; conquistado o sul até a margem setentrional do Prata e todo o oeste até o Paraguai, o Madeira e o Javari, ficando assim definida a sua configuração geográfica", entretanto, a sua administração era ainda uma paisagem de desordem.

(1) JoÃo Ribeiro - História do Brasil, 14, ${ }^{a}$ ed. - Rio, 1953.

(2) Francisco Adolfo de VARnhagen - História Geral do Brasil, 4. ${ }^{a}$ ed. Rio, 1952 . 
Continuava-se no regime dos monopólios das companhias de comércio, célebres desde as das Indias Ocidentais e que, em Portugal, a primeira fôra criada em 1649. Outras emprêsas dessa natureza ainda permaneceram na administração pombalina. Em 1755 e 1759 existiam as companhias de comércio, a do Grão-Pará e Maranhão e a de Pernambuco e Paraíba, que, além do mais, desenvolviam a cultura do arroz, da cana de açúcar, do algodão, cacau e café. (3) Essas companhias, como nos mostra a história econômica, também desenyolveram a indústria e a pecuária "couro, castanha, óleos vegetais, etc".

Vê-se, dêste modo, que, até à chegada de Pombal ao Brasil, ainda nos faltava uma diretiva politico-civil-administrativa que abarcasse os principais problemas da incipiente administração da Colônia.

Ao tomar contato com a realidade brasileira, o marquês de Pombal promovera, como dos primeiros atos, a dissolução do Estado do Maranhão e o "resgate e confisco das últimas capitanias hereditárias, em número aproximaciamente de sete".

Pondo em prática métodos diferentes de administrar, dentro, evidentemente, do seu espírito despótico, mas dosado do liberalismo enciclopédico, volveu-se Pombal para aspectos do direito amplo que, desde 1534, havia sido dado aos capitães-mores. Anexou capitanias, deu governadores a Pernambuco e Bahia, passando a residência dos governadores para o Rio de Janeiro (1773).

Tomando medidas de organização administrativa, Sebastião José de Carvalho e Melo não esqueceu a justiça, o que demonstra o seu aprêço às idéias dos direitos do homem, e que se estampa naquela providência corajosa de exinguir a inquisição e os direitos temporais do clero.

A fim de dar liberdade aos índios, o que iria decerto desagradar a política reinante, Pombal promoveu uma imigração de mais de 20.000 almas, vindas dos Açores para o Brasil, e que supririam o comércio, a lavoura e a indústria.

Com a quebra do monopólio comercial, como bem argumenta João Ribeiro, criaram-se bancos em Grão-Pará e em Pernambuco, que vinham estabilizar os processos de organização administrativa de Pombal na grande Colônia Americana, que assim passava a apresentar aspectos novos e novos rumos, tanto jurídica quanto administrativamente.

Mas, o famoso ministro de $\mathrm{D}$. José procurava familiarizar-se com as necessidades da terra imatura e queria por todos os meios desenvolver as suas fontes de vida e riqueza, o que se demonstra com o seu amparo às minas, levando ao mesmo tempo às terras montanhesas não sòmente a ajuda na caça de ouro e pedras preciosas, como também fundando colégios que, segundo a crônica, ainda hoje lá existem, como marcos da sua visão de administrador.

Conhecedor das incursões dos flibusteiros, nos primeiros séculos, Pombal não descurou do aparelhamento do exército, do equipamento e construção de fortalezas, com o intuito de tornar mais viva e pronta a defesa do Brasil, contra os avanços estrangeiros.

\footnotetext{
(3) Basílio de Magalhães - Manual de História do Brasil - Rio, 1946.

(4) BAsílio DE MAGALHĀES - História do Brasil - Rio, 1943.
} 
As providências de caráter administrativo implantadas pelo marquês de Pombal no Brasil se enquadram perfeitamente nos ensinamentos de administração científica, só postos em prática séculos mais tarde, como se vê nas páginas de um dos maiores tratadistas americanos, quando afirma: "O principal objetivo da administração deve ser assegurar o máximo de prosperidade ao empregado". (5)

Ora, era isso precisamente que, consciente ou não, como que por intuição natural, procurava fazer o ministro de D. José I, ao tentar organizar administrativamente o Brasil.

Mas, convém salientar ainda que Pombal teve outras iniciativas que devem ser apontadas e que demonstram o seu tino de organizador e homem público enérgico e objetivo. Entre elas se inclui o incremento que deu ao ensino primário, abrindo escolas públicas por tôda parte, como quem constrói, pela instrução, uma nacionalidade para o futuro.

Regulamentando o comércio do diamante, fundou um Tribunal de Apelação no Rio e reduziu os impostos do tabaco e do açúcar, como ainda facilitou e estimulou o casamento de portuguêses e índios.

Acusam-no da expulsão dos jesuítas do Brasil. Na realidade, porém, por mais violento que tenha sido o seu ato, no momento era uma providência imposta pelas circunstâncias, uma vez que, desrespeitado o tratado de Madrid, de 1750, pelo qual a Espanha ficava com a Colônia do Sacramento de Portugal com Sete Missões, (6) pela revo1ta dos índios instigados pelos jesuítas, perigava a segurança da novel nacionalidade.

Forte personalidade, misto de liberalismo e despotismo, que representava em Pombal a luta instintiva entre a formação inicial e o convívio, a assimilação da fase transitória das novas idéias francesas que haveriam de dominar o mundo, a sua administração no Brasil, naqueles meados do século XVIII, projetou-se como um delineamento positivo que, mesmo combatido, mesmo discutido, mesmo condenado ou endeusado, forçoso é reconhecer, estabeleceu um divisor na vida brasileira, que se define: antes de Pombal; depois de Pombal.

Administrou Pombal dentro dos princípios da economia de Quesnay, de Turgot, de Smith, pois que, embora a obra de Smith, Da riqueza das nações só haja saído a lume em 1776, mesmo assim já estavam em voga as suas teorias de protecionismo, às quais não escaparam nem Nicker, nem Bonaparte. (7) Eram as doutrinas econômicas lançadas em 1756, na enciclopédia.

"Destituindo-o da preeminência religiosa, reduzindo-o a simples magistratura civil, humanizando-lhe as regras do processo, e proibindo-lhe os autosde-fé, as reformas de Pombal "significam uma profunda revolução no regime do Santo Ofício... Revolução foi o gênero dêsse estadista, em quase todos os assuntos onde penetrou." (8)

(5) FREDERICK TAYLoR - Princípios de Administração Científica, tradução de Arlindo Vieira Ramos - Rio, 1948.

(6) Veiga Cabral - História do Brasil - 18. a ed. - Rio, 1954.

(7) Rui Barbosa - O Marquês de Pombal - Rio, 1951.

(8) Rui Barbosa - O Marquês de Pombal - Rio, 1951. 
Para o estudo e criação da sociologia administrativa do Brasil, a fase pombalina na administração brasileira será de importância singular, uma vez que, com o amparo à lavoura, à pecuária, às minas, não esqueceu o estadista luso o problema do ensino e da instrução, importante a qualquer organização daquela natureza, e ainđa, o que é mais singular, livrou o brasilindio, permitindo-lhe casar livremente com portuguêses e tirou-o da condição de mera propriedade dos jesuítas.

E essa sociologia administrativa se evidenciará ainda mais, sabendo-se como se sabe que, o século XVIII, em que atuara Pombal, foi o século da grande preparação do XIX, notando-se em seus meados a existência de núcleos culturais na Bahia e no Rio, sociedades literárias e grande espírito de sátina. (10)

Com certa limitação à ordem econômica, sobreveio melhor feição política à Colônia, salientando-se mais os núcleos hunanos de Salvador, São Luiz do Maranhão, Olinda, Belém do Pará, São Paulo e Rio de Janeiro. (11)

A colônia luso-americana, quanto à justiça, "estêve sujeita às leis manuelinas" e depois às ordenações do Reino, mas a partir de Pombal encontra-se uma trilha administrativa diferente, com leiş extraordinárias que, compreendidas e interpretadas no século XVIII, com a nossa evidente evolução sóciocultural, deixam margem ao estudo da sociologia administrativa, pois que, com elas, conseguiu Pombal objetivar uma obra multiforme, em que abarcou todos os problemas do país, problemas que se nucleam num sentido social, econômico e cultural. Estampam-se pois nos elementos dispersos em algumas fases marcantes da vida administrativa do Brasil, sobretudo em Pombal e Nassau, fenômenos sociológicos claros e precisos, que devem ser esquematizados à luz da ciência e que melhormente virão determinar a nossa posição na comunhão pan-americana, no trato da ađministração pública.

\section{SUMMARY}

1. The liberal "apprenticeship" of the Marquis of Pombal as a diplomat, and the Iiffluence of the 18th century "Encyclopaedism" upon his policies of statesman and mirister to King José 1 .

2. The Portuguese Inquisition and the autos-de-fé abolished. The Jesuits expelled from Brazil. The Jesuits had incited the natives of the "Seven Missions" to rebel against the Portuguese. According to the Treaty of Madrid the territory of the "Missions" was under the sovereignty of Portugal.

3. The trade companies of Grão-Pará and Maranhão, and of Pernambuco and Paraiba, which had rights of monopoly to operate in Brazil, also abolished.

4. The "state" of Maranhão as distinct from the "state" of Brazil abolished. The last hereditary captaincies confiscated. Crovernors appointed to Bahia and Pernambuco. The seat of the Governor-general transferred to Rio de Janeiro.

(9) Basílio de Magalhães - ob. cit.

(10) Rocha Pомво - História do Brasil, 6. ${ }^{\text {a }}$ ed. - Rio, 1952.

(11) Basílio de MagalHães - obs. cits. 
5. Immigration of 20,000 inhabitants from the Azores to Brazil. Schools established ir: the hinterland. The armed forces better trained and equipped; forts built along the coast as means of protection against the filibusters.

6. The diamond trade regulated; a Court of Appeals instituted in Rio de Janeiro; taxes upon tobbacco and sugar reduced. The old Portuguese ("Manueline") legislation superseded.

7. The Marquis of Pombal as a disciple of Quesnay, Turgot and Adam Smith.

8. General conclusion: the necessity of studying the Marquis of Pombal's era in the light of administrative sociology; its contributions towards our present-day administrative policies.

O direito administrativo é um ramo do direito de desenvolvimento relativamente recente. Tomou importância maior com o movimento de estabilização que se vem processando nestes últimos vinte anos, sob a influência de uma nova política social, em que o Estado se apresenta dentro de uma finalidade tutelar de inconfundivel importância .

O desequilíbrio e o desnivelamento econômico, o pauperismo, a luta de classe, colocaram o Estado na contingência de intervir, com o objetivo superior de restabelecer o equilibrio, ou pelo menos de minorar os efeitos do desequilíbrio econômico e social, trazendo, para aquêles que não podem por si só, o apoio, o amparo, a proteção, suprindo as necessidades elementares da vida.

O Estado, para isso, criou novos serviços, interveio em uma esfera, destinada anteriormente à iniciativa privada; teve portanto de ampliar extraordinàriamente os seus quadros administrativos.

Ao serviço de administração entraram novos técnicos, o aparelho puramente bürocrático tomou expressão nova, procurando aproximar-se das grandes organizações administrativas particulares.

A Ciência da administração perdeu o seu caráter rotineiro, primitivo, tomando uma feição técnica, e alargou o seu campo de estudos para as diversas ciências ligadas aos problemas administrativos:

* O direito ad̉ministrativo tornou-se então, disciplina preponderante no quadro do direito público, em virtude da importância dos problemas administrativos sôbre os políticos no conjunto das atividades do Estado.

Daí a tendência ùltimamente verificada, mesmo nos países de organização mais nìtidàmente democrática, para aumentar a ação do poder regulamentar, bem como para admitir em maior escala as delegações legislativas.

(O Direito Administrativo - Themístocles Brandão Cavalcanti - In Rev. do Serv. Público - abril de 1940 , p. 68 ). 